\title{
Silencing of IKKe using siRNA inhibits proliferation and invasion of glioma cells in vitro and in vivo
}

\author{
HUIBING LI $^{1,2^{*}}$, LINGCHAO $\mathrm{CHEN}^{3^{*}}$, ANLING ZHANG ${ }^{1,2}$, GUANGXIU WANG $^{1,2}$, LEI HAN $^{1,2}$, \\ KAI YU ${ }^{1,2}$, PEIYU PU ${ }^{1,2}$, CHUNSHENG KANG ${ }^{1,2^{* *}}$ and QIANG HUANG ${ }^{1,2^{* *}}$ \\ ${ }^{1}$ Laboratory of Neuro-Oncology, Tianjin Neurological Institute; ${ }^{2}$ Department of Neurosurgery, \\ Tianjin Medical University General Hospital, Tianjin 300052; ${ }^{3}$ Department of Neurosurgery, the \\ Second Affiliated Hospital of Harbin Medical University, Harbin 150086, P.R. China
}

Received January 20, 2012; Accepted March 16, 2012

DOI: $10.3892 /$ ijo.2012.1452

\begin{abstract}
Recent studies implicated IKKe in the pathogenesis of many human cancers by promoting cell proliferation, increasing tumor angiogenesis and metastasis, and generating resistance to cell apoptosis. However, whether IKKe can influence the invasive ability and proliferation of glioma cells remains largely unknown. In this study, we showed that overexpression of $\mathrm{IKK} \varepsilon$ is positively correlated to glioma pathological grade, suggesting that IKKe plays a role in tumor progression, rather than tumor initiation. Targeted knockdown of IKKe in human glioma cells using siRNA, was associated with inhibition of cell growth, cell cycle arrest and decreased cell invasion; however, notable apoptosis was not observed. Furthermore, we demonstrated that transposition of NF- $\kappa$ B p65 resulted in the alteration of these phenotypes. Tumor growth was attenuated in established subcutaneous gliomas in nude mice treated with IKKe siRNA in vivo. Collectively, our results suggest that deregulation of IKKe plays a pivotal role in the uncontrolled proliferation and malignant invasion of glioma cells in vitro and in vivo by targeting NF- $\kappa \mathrm{B}$. Silencing of IKKe using synthetic siRNAs may offer a novel therapeutic strategy for the treatment of glioma.
\end{abstract}

\section{Introduction}

Gliomagenesis is a complex and multifactorial process with multiple genetic alterations, and is characterized by rapid cell proliferation, high invasion, genetic alteration and increased

Correspondence to: Dr Qiang Huang, Department of Neurosurgery, Tianjin Medical University General Hospital, Laboratory of Neurooncology, Tianjin Neurological Institute, Tianjin 300052, P.R. China E-mail: huangqiang209@yahoo.com.cn

\section{*Contributed equally}

${ }^{* *}$ Senior authors

Key words: glioma, IKKe, proliferation, invasion angiogenesis $(1,2)$. Despite technical advances in neurosurgery, radiation therapy and clinical trials, the prognosis of patients with glioma is poor, with a mean survival time of 9-12 months $(3,4)$. IKK $\varepsilon$ is involved in regulating the activation of the type I IFN and NF- $\kappa \mathrm{B}$ signaling pathways, and was initially identified in a subtractive hybridization screen as a lipopolysaccharide (LPS)-inducible gene and as a PMA-inducible protein. The kinase domain of IKKe is $27 \%$ identical to IKK $\alpha$ and IKK $\beta$ $(5,6)$. It has been suggested that IKKe is involved in TNF $\alpha$ and LPS-induced matrix metalloproteinase-3 and matrix metalloproteinase-13 gene expression via phosphorylation and activation of the c-JUN pathway. This pathway may be responsible for synovial inflammation and extracellular matrix destruction in rheumatoid arthritis, as well as being involved in tumor invasion and metastasis (7). Eddy et al demonstrated that overexpression of a kinase-inactive form of IKKe in breast cancer cells reduced the expression of $\mathrm{NF}-\kappa \mathrm{B}$ target genes, cyclin D1 and RelB, as well as anchorage-independent growth and invasion in Matrigel (8). Subsequently, IKKe was shown to activate basal levels of $\mathrm{NF}-\kappa \mathrm{B}$ via phosphorylation of serine 536, and inhibition of this activity significantly suppressed cancer cell proliferation (9). IKKe was identified as a breast oncogene using complementary genomic approaches in over $30 \%$ of breast cancer cell lines and carcinomas. Abnormal upregulation of $\mathrm{NF}-\kappa \mathrm{B}$ activity by IKKe was presumed to be an essential step for cell transformation (10). Guo et al showed that $\mathrm{IKK} \varepsilon$ is overexpressed in a significant proportion of ovarian carcinomas (63/95), and elevated IKKع levels served as a marker for poor prognosis (11). IKKe is also reported to promote prostate cancer progression, by inducing secretion of IL-6, which may act as a positive growth factor in prostate cancer (12). Taken together, these data strongly support the role of IKKe in tumorigenesis, and indicate that blocking IKKe expression may represent a rational therapeutic strategy.

In the present study, we demonstrated that IKKe is frequently overexpressed in human glioma. Targeted knockdown of IKKe using synthetic siRNAs dramatically inhibits the proliferative and invasive ability of tumor cells and the expression of proteins associated with these phenotypes in vitro and in vivo. Our data indicated that IKKe may represent a promising therapeutic target for the treatment of glioma. 


\section{Materials and methods}

Tissue samples. Seven normal brain tissue and 51 neurospongioma specimens were obtained during surgical resection from patients at Huanhu Hospital during 2010. The pathological diagnosis and grading of glioma specimens was assessed according to WHO guidelines (2000). Glioma specimens consisted of 5 cases of pilocytic astrocytoma (Grade I), 11 cases of astrocytoma (Grade II), 8 cases of oligodendroglioma (Grade II), 9 cases of anaplastic astrocytoma (Grade III), 6 cases of anaplastic oligodendroglioma (Grade III) and 12 cases of glioblastoma (Grade IV). All tissue samples were collected in accordance with institutional review board-approved protocols. A sample of all tissues was snap-frozen and stored at $-80^{\circ} \mathrm{C}$, and the remaining portion was fixed with $10 \%$ formalin for histopathological and immunohistochemical examination.

Cell culture and transfection. The human U251 and LN229 glioblastoma cell lines were purchased from the Institute of Biochemistry and Cell Biology. All cell lines were maintained in Dulbecco's modified Eagle's medium (DMEM, Gibco, USA) supplemented with $10 \%$ fetal bovine serum (FBS), and maintained at $37^{\circ} \mathrm{C}$ in $5 \% \mathrm{CO}_{2}$. Prior to transfection, cells were plated in six-well plates and incubated for $24 \mathrm{~h}$. Cells were transfected in serum-free medium with $10 \mathrm{ng} / 5 \mu \mathrm{l}$ siRNA using Lipofectamine (Invitrogen, Carlsbad, CA, USA). After 4h, medium was replaced with DMEM supplemented with $10 \%$ FBS and cells were incubated at $37^{\circ} \mathrm{C}$ in $5 \% \mathrm{CO}_{2}$. The siRNA sequences targeting IKKe were: siR-1: 5'-GGUCUUCAACACUACCAGCTT-3'; siR-2: 5'-GAGCTATCTCACCAGCTCC-3'; siR-3': 5'-GCUGAACCAC CAGAACAUCTT-3'; siR-4: 5'-GAAGCATCCAGCAGAT TCA-3'; siR-5: 5'-TGGCAGGAGCTAATGTTTCG-3'.

Real-time PCR analysis. Total RNA was extracted with TRIzol (Gibco, Carlsbad, CA, USA) $48 \mathrm{~h}$ after transfection, and reverse transcription was performed using AMV reverse transcriptase (Takara, Shiga, Japan) according to the manufacturer's protocol. Quantitative real-time PCR was performed with $100 \mathrm{ng}$ of cDNA using SYBR Green-1 dye universal Master mix on a real-time PCR cycler (7500 ABI, USA). Primer sequences used for quantitative PCR are shown in Table I. The reaction conditions were as follows: $95^{\circ} \mathrm{C} 10 \mathrm{~min}, 95^{\circ} \mathrm{C} 15 \mathrm{sec}, 60^{\circ} \mathrm{C} 1 \mathrm{~min}$, $60^{\circ} \mathrm{C} 1 \mathrm{~min}, 40$ cycles. $\beta$-actin was used as control. The results of real-time PCR were analyzed using the $\Delta \Delta \mathrm{CT}$ method: $\Delta \mathrm{CT}=\mathrm{CT}_{\text {selected gene }}-\mathrm{CT}_{\beta \text {-actin }}, \Delta \Delta \mathrm{CT}=\Delta \mathrm{CT}_{\text {therapy group }}-\Delta \mathrm{CT}_{\text {control group }}$, $\mathrm{RQ}$ (relative quantitation) therapy group $=2^{-\Delta \Delta \mathrm{CT}}, \mathrm{RQ}$ control group $=1$. Real-time results are presented as the ratio between the selected genes and $\beta$-actin transcripts.

Western blot analysis. Total cell lysates were prepared using RIPA lysis buffer containing freshly added protease and phosphatase inhibitors (GENMED, Shanghai, China). Cell lysates were clarified by centrifugation at $4^{\circ} \mathrm{C}$ for $10 \mathrm{~min}$ at $12,000 \mathrm{rpm}$. Cytoplasmic and nuclear NF- $\mathrm{KB}$ p65 protein sub-fractions were prepared using a commercial extraction kit (Active Motif, Tokyo, Japan) according to the manufacturer's instructions. Protein concentration was determined using a BCA protein assay kit (Pierce, Rockford, IL, USA). Proteins $(20 \mu \mathrm{g})$ were resolved by SDS-PAGE and electrotransferred to PVDF membranes (Millipore, Billerica, MA, USA). Antibodies used were IKK $\varepsilon$ (Sigma, St. Louis, MO, USA), CCND1, VEGF,

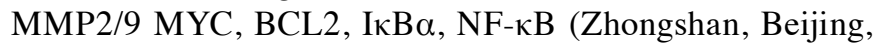
China) and GAPDH (Santa Cruz). All antibodies were used at a dilution of 1:1000. Proteins were detected using the SuperSignal protein detection kit (Pierce).

Focus formation assays. Cells/well $\left(5 \times 10^{3}\right)$ were seeded in six-well plates $48 \mathrm{~h}$ after transfection. Growth medium was changed every 2 days. After 9 days, cells were washed twice with ice-cold growth medium, fixed in ice-cold methanol and stained with $0.5 \%$ crystal violet. Colonies ( $\geq 50$ cells) were scored using a microscope (Olympus, Japan). Plate clone formation efficiency was calculated as follows: [(number of colonies/number of cells inoculated) x100]. Each experiment was performed in triplicate.

Cell viability assays. Cell viability was assessed over a 6-day period. Cells were seeded (2x103/well) into 96-well plates $48 \mathrm{~h}$ after transfection. $20 \mu 1$ of MTT reagent (Sigma) was added into each well and incubated for $4 \mathrm{~h}$ at $37^{\circ} \mathrm{C}$ in a $\mathrm{CO}_{2}$ incubator. DMSO $(200 \mu \mathrm{l})$ was added to each well and optical density was measured at the wavelength of $570 \mathrm{~nm}$. The data are presented as the mean $\pm \mathrm{SD}$, derived from triplicate samples of three independent experiments.

Cell cycle analysis. Cell cycle analysis was performed $48 \mathrm{~h}$ after transfection. Cells were trypsinized, washed with PBS and fixed with $75 \%$ ethanol overnight at $4^{\circ} \mathrm{C}$. Cells were washed twice with PBS and incubated with $200 \mu \mathrm{l}$ RNase $(1 \mathrm{mg} / \mathrm{ml})$ at $37^{\circ} \mathrm{C}$ for $30 \mathrm{~min}$. Cells were stained with $800 \mu 1$ propidium iodide staining solution for $30 \mathrm{~min}$ at $4^{\circ} \mathrm{C}$. A total of 10,000 nuclei were analyzed by use of a FacsCalibur flow cytometer (Bio-Rad, Hercules, CA, USA) and the DNA histograms were generated by Modifit software (Becton-Dickinson, USA).

Apoptosis assays. Apoptotic cells were identified $48 \mathrm{~h}$ after transfection. In brief, after siRNA treatments, both floating and attached cells were collected and subject to Annexin V/PI staining using the Annexin V-FITC Apoptosis Detection kit I (Abcam, Cambridge, MA, USA) according to the manufacturer's instructions. Flow cytometric analysis was performed on a FACS flow cytometer (Becton-Dickinson). Data were analyzed by CellQuest software.

Wound healing assays. U251 and LN229 cells were seeded in 6-well plates $\left(2 \times 10^{5}\right.$ cells/well $)$ and transfected with $10 \mathrm{ng} / 5 \mu \mathrm{l}$ siRNA. $48 \mathrm{~h}$ after transfection ( $90 \%$ confluency), a wound area was carefully created by scraping the cell monolayer with a sterile $100 \mu 1$ pipette tip. The cells were then washed with PBS to remove detached cells and fresh growth media was added. Cells were then incubated at $37^{\circ} \mathrm{C}$ and the width of the wound area was monitored with an inverted microscope at various time points. The normalized wound area was calculated using TScratch software (13).

Cell invasion assays. Transwell filters (Costar, USA) were prepared by coating with Matrigel on the upper surface of the polycarbonic membrane. The Matrigel was set for $30 \mathrm{~min}$ at $37^{\circ} \mathrm{C}$, allowing it to be used as an extracellular matrix for tumor cell invasion analysis, and $48 \mathrm{~h}$ after transfection, $1 \times 10^{5}$ cells 
Table I. Gene specific primers.

\begin{tabular}{lll}
\hline Gene & \multicolumn{1}{c}{ Forward primer } & \multicolumn{1}{c}{ Reverse primer } \\
\hline IKBKE & 5'-TGCGTGCAGAAGTATCAAGC-3' & 5'-TACAGCAGCCACAGAACAG-3' \\
Cyclin D1 & 5'-AACTACCTGGACCGCTTCCT-3' & 5'-CCACTTGAGCTTGTTCACCA-3' \\
MMP9 & 5'-TTGGTCCACCTGGTTCAACT-3' & 5'-ACGACGTCTTCCAGTACCGA-3' \\
VEGF & 5'-CCCACTGAGGAGTCCAACAT-3' & 5'-TTTCTTGCGCTTTCGTTTTT-3' \\
Bcl-2 & 5'-GAGGATTGTGGCCTTCTTTG-3' & 5'-ACAGTTCCACAAAGGCATCC-3' \\
MYC & 5'-TTCGGGTAGTGGAAAACCAG-3' & 5'-CAGCAGCTCGAATTTCTTCC-3' \\
$\beta$-actin & 5'-CTCCATCCTGGCCTCGCTGT-3' & 5'-GCTGTCACCTTCACCGTT-3'
\end{tabular}

were resuspended in $100 \mu \mathrm{l}$ of serum-free DMEM and added to the upper chamber of transwells. Conditioned medium from U251 and LN229 cells (200 $\mu \mathrm{l})$ was used as chemoattractant and placed in the bottom chamber. Cells were allowed to migrate for $48 \mathrm{~h}$ at $37^{\circ} \mathrm{C}$ in a $\mathrm{CO}_{2}$ incubator. Non-invading cells were removed from the upper side of the chamber with a cotton swab and inserts containing migrated cells were then fixed with $100 \%$ methanol, stained with hematoxylin, mounted and dried at $80^{\circ} \mathrm{C}$ for $30 \mathrm{~min}$. The number of cells invading the Matrigel were counted from ten randomly selected visual fields, each from the central and peripheral portion of the filter, using an inverted microscope at x200 magnification. Experiments were performed in triplicate.

Immunofluorescence and immunohistochemical staining. For immunofluorescence staining, cells were seeded onto sterile cover slips $48 \mathrm{~h}$ after transfection and incubated for $2 \mathrm{~h}$ at $37^{\circ} \mathrm{C}$. Cells were washed twice with ice-cold PBS and fixed with $2 \%$ formaldehyde for $30 \mathrm{~min}$. Cells were then permeabilized with $0.1 \%$ Triton X-100 and blocked in 2\% BSA for 30 min at room temperature. Cells were incubated with primary anti-NF- $\mathrm{B}$ p65 antibody (Sigma, 1:100 dilution) at $4^{\circ} \mathrm{C}$ overnight. Samples were washed with PBS and incubated with species-specific secondary antibodies (1:100 dilution) in PBS for $30 \mathrm{~min}$. Immunofluorescence was examined using a confocal microscope (Olympus FV1000S, Japan). For immunohistochemistry, sections were dewaxed, treated with $3 \% \mathrm{H}_{2} \mathrm{O}_{2}$ for $10 \mathrm{~min}$ and incubated with appropriate antibodies (1:100 dilution) at $4^{\circ} \mathrm{C}$ overnight. Sections were incubated with biotinylated secondary antibody (1:100 dilution) for $1 \mathrm{~h}$ at room temperature, followed by incubation with ABC-peroxidase for $1 \mathrm{~h}$. After washing with Tris-buffer, sections were incubated with DAB (3,3'-diaminobenzidine, $30 \mathrm{mg}$ dissolved in $100 \mathrm{ml}$ Tris-buffer containing $0.03 \% \mathrm{H}_{2} \mathrm{O}_{2}$ ) for $5 \mathrm{~min}$, washed in water and counterstained with hematoxylin.

Xenograft tumor assay. Six-week old female immune-deficient nude mice (BALB/C-nu) were purchased from the animal center of the Cancer Institute, Chinese Academy of Sciences. Animals were housed in individual micro-isolator cages at the facility of laboratory animals, Tianjin Medical University. All experiments were carried out according to the regulations and internal biosafety and bioethics guidelines of Tianjin Medical University and Tianjin Municipal Science and Technology Commission. Mice $(n=3)$ were injected subcutaneously with
Table II. IKKe expression and clinical pathological characteristics.

\begin{tabular}{|c|c|c|c|}
\hline Variable & Low/no & $\begin{array}{c}\text { IKKE } \\
\text { High/moderate }\end{array}$ & P-value \\
\hline \multicolumn{4}{|l|}{ Sex } \\
\hline Male & 9 & 19 & \\
\hline Female & 8 & 15 & 0.538 \\
\hline \multicolumn{4}{|l|}{ Age } \\
\hline$\leq 43$ & 8 & 11 & \\
\hline$>43$ & 10 & 22 & 0.313 \\
\hline \multicolumn{4}{|l|}{ Grade (WHO) } \\
\hline $\mathrm{I} / \mathrm{II}$ & 21 & 3 & \\
\hline III/IV & 4 & 23 & 0.000 \\
\hline \multicolumn{4}{|l|}{ Histology } \\
\hline Astrocytic & 7 & 30 & \\
\hline Oligodendroglioma & 5 & 9 & 0.185 \\
\hline
\end{tabular}

$6 \times 10^{6} \mathrm{U} 251$ cells in a $200 \mu \mathrm{l}$ volume. Mice were monitored daily for tumor formation. Tumors of approximately $5 \mathrm{~mm}$ in diameter were surgically removed, and $1-2 \mathrm{~mm}^{3}$ sections were implanted into individual mice $(n=12)$. When tumors reached approximately $5 \mathrm{~mm}$ in diameter, mice were divided into two groups, IKKe siRNA $(n=6)$ and siRNA-NC (non-sense siRNA). Twenty five microliters of a mixture containing $150 \mu \mathrm{l}$ siRNA (IKK $\varepsilon$ siRNA or siRNA-NC, $20 \mathrm{pmol} / \mu \mathrm{l}$ ) and $60 \mu \mathrm{l}$ oligofectamine was injected into subcutaneous tumors using a multi-site-injection method. Tumor volume was assessed for a period of three weeks by measurement with a caliper every 2 days using the formula: volume $=$ length $\mathrm{x}$ width ${ }^{2} / 2$. Mice were sacrificed after three weeks and tumors were excised and prepared as paraffin-embedded sections for detection of the expression of IKKe, MMP2/9, cyclin D1, PCNA, VEGF and c-myc by immunohistochemical staining.

Statistical analysis. All data represent the average of at least three biological replicates or as indicated \pm standard deviation (SD). Statistical analyses were carried out using the SPSS 16.0. $\mathrm{P}<0.05$ is considered to be statistically significant by ANOVA and $\chi^{2}$ test. 
$\mathbf{A}$
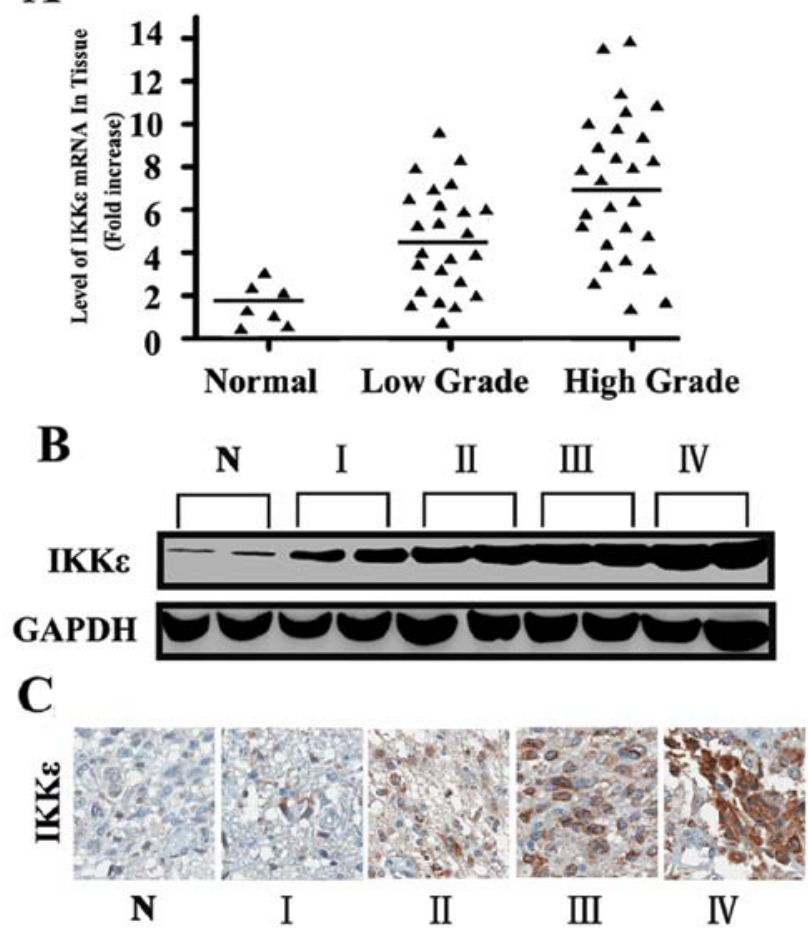

Figure 1. IKKe is highly expressed in human gliomas specimens. (A) Expression of IKKe mRNA in different grades of human gliomas specimens examined by quantitative real-time PCR. (B) Western blot analysis show that human gliomas specimens grade I-IV express higher levels of IKKe compared with normal brain tissues. (C) IKKe expression in different grades of human glioma specimens detected by immunohistochemistry (x200).

\section{Results}

$I K K \varepsilon$ is frequently overexpressed in glioma and correlates with tumor grade. IKKe was recently identified as a breast cancer oncogene, with amplification detected in $16 \%$ breast cancers and overexpression of IKK $\varepsilon$ protein observed in nearly half of primary breast tumors (10). In our study, overexpression of IKK $\varepsilon$ mRNA and protein was detected in 45 of 51 frozen glioma specimens (88.2\%), whereas IKKe expression was either absent or expressed at low levels in normal brain tissue (1/7) (Fig. 1A and B). Immunohistochemical staining of the same panel of glioma specimens with anti-IKKe antibody also showed that IKK $\varepsilon$ expression was significantly increased in glioma compared with normal brain, with expression restricted to the cytoplasm (Fig. 1C). While Guan et al previously demonstrated that IKKe is upregulated in glioma cell lines and primary human glioma specimens, no significant difference in IKKe expression among different grades of glioma was observed (14). In contrast, our analyses show that IKK $\varepsilon$ expression positively correlated with tumor grade (Fig. 1A-C). IKKe overexpression was relatively low in low grade glioma and increased in high grade tumors $(\mathrm{P}=0.000$; Table II), suggesting that alterations of IKK $\varepsilon$ may be involved in glioma progression rather than initiation. We next examined the relationships between IKKe overexpression and clinicopathological features of glioma. We observed that IKKE is frequently overexpressed in glioblastoma $(11 / 12,91.6 \%)$ compared with other histological types of glioma. However, we did not observe any differences in IKKe expression related to age, gender and histology.

Silencing of IKKE expression in glioma cells by siRNA knockdown. We tested the ability of five siRNAs designed to target different regions of the IKK $\mathrm{mRNA}$, to reduce IKK $\varepsilon$ expression in U251 and LN229 cells. Analysis of IKKe expression $48 \mathrm{~h}$ after transfection by quantitative real-time PCR, revealed that all five siRNAs were capable of silencing IKKe expression to varying degrees when compared with control scrambled siRNA (Figs. 2A and B). The most efficient knockdown was observed with siRNA-3 $(\mathrm{p}<0.05)$, which was selected for use
A
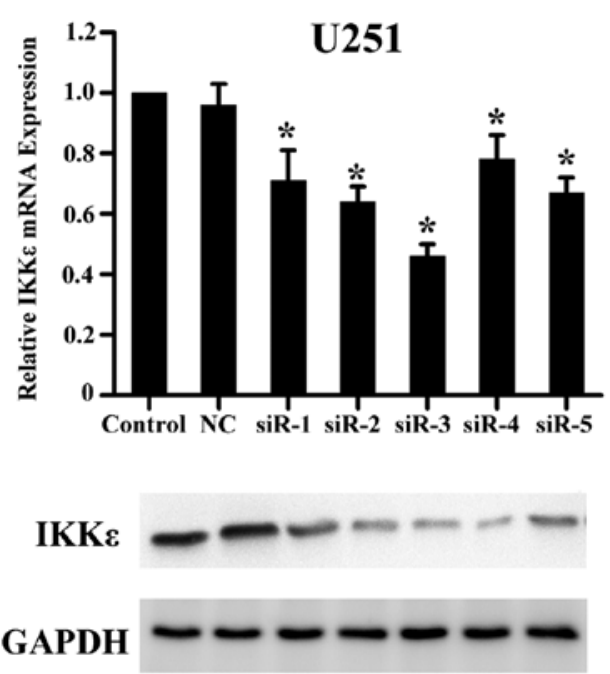

Control NC siR-1 siR-2 $\operatorname{siR-3}$ siR-4 $\operatorname{siR-5}$
B

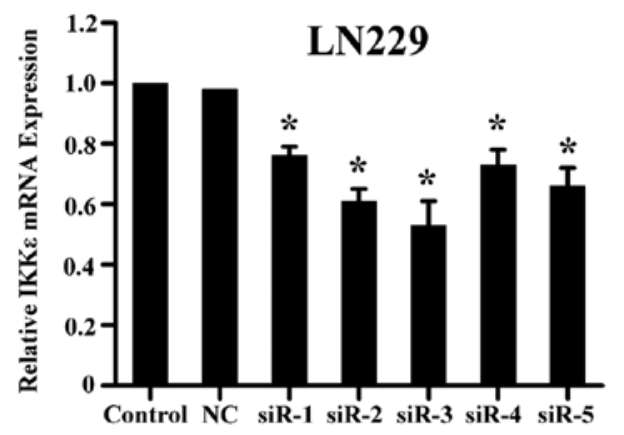

IKK $\varepsilon$

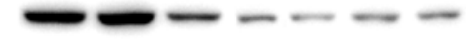

GAPDH

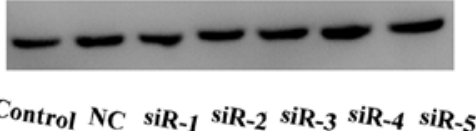

Figure 2. IKKe expression is effectively inhibited by targeted knockdown using siRNA. (A and C) IKKe expression in U251 treated with siRNA-NC and siRNA1-5 was determined by quantitative real-time PCR and western blot analysis, all five siRNAs showed a significant silencing effect (P<0.05) and in comparison with scrambled siRNA. (B and D) IKKe expression in LN229 treated with siRNA-NC and siRNA1-5 was determined by quantitative real-time PCR and western blot analysis. Among them, siR-3 showed the greatest suppression of IKKe and therefore siR-3 was selected for subsequent biological studies. 
A
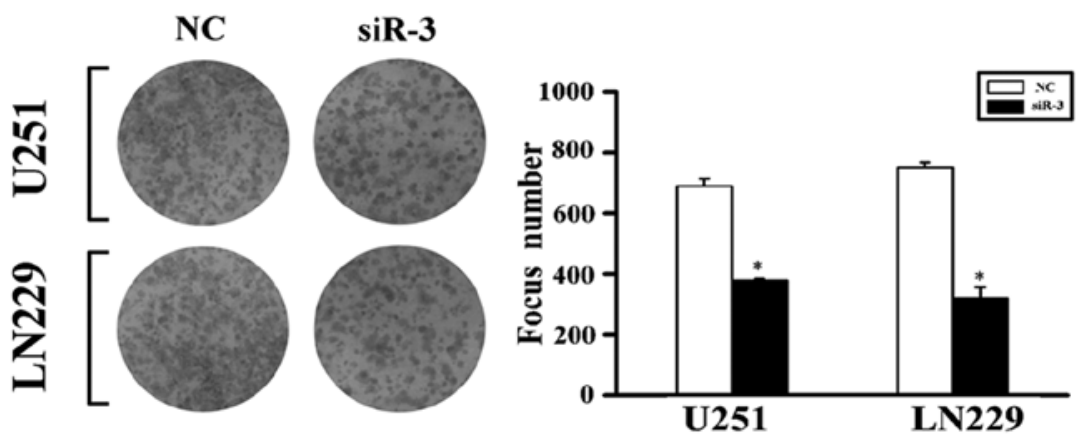

B

U251
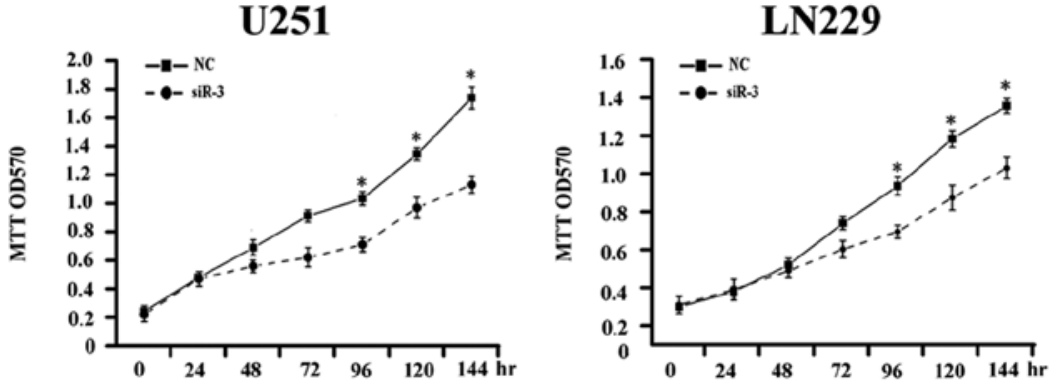

C
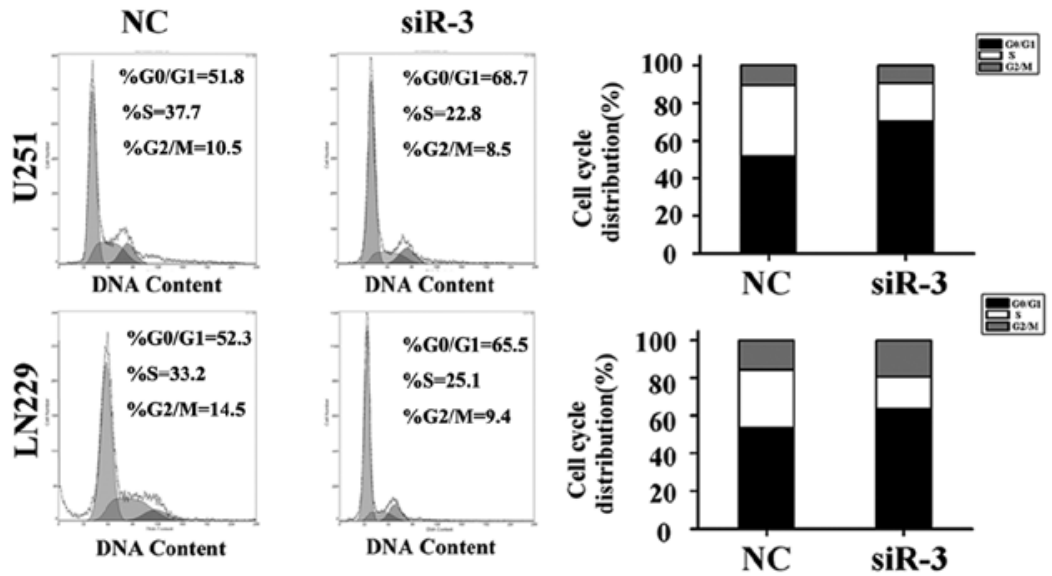

Figure 3. Silencing IKKe expression suppresses proliferation in vitro. (A) Focus formation assays in U251 and LN229 cells transfected with siR-3 or scrambled control (siRNA-NC). (B) Proliferation rate of U251 and LN229 cells transfected with IKK $\varepsilon$ siRNA determined by MTT assay, knockdown of IKK $\varepsilon$ significantly inhibited cell proliferation compared to the cells treated with scramble oligonucleotides. (C) Cell cycle analysis examined in U251 and LN229 cells transfected with siRNA-3 or siRNA-NC ( $\mathrm{P}<0.05)$. Flow cytometry data represented low expression of IKKe induced G0/G1 cell cycle arrest.

in future loss of function experiments. Western blot analysis confirmed knockdown of IKKe at the protein level (Figs. 2C and D).

Downregulation of IKKE inhibits glioma cell proliferation and inhibits foci formation. To test whether downregulation of IKKe in glioma cells affects the anchorage-independent growth capability, we performed focus formation assays in cells transfected with IKKe siRNA. As shown in Fig. 3A, U251 cells treated with IKKe siRNA exhibited decreased foci formation and smaller foci diameter compared with control siRNA cells. Similar results were also observed in LN229 cells. These data indicate that inhibition of IKKe markedly decreases anchorageindependent growth potential. We next assessed the effect of loss of IKKe on U251 and LN229 cell proliferation by MTT assay.
Cell proliferation was significantly impaired in cells transfected with IKK $\varepsilon$ siRNA in a time-dependent manner, compared with control cells (Fig. 3B). These results demonstrate that IKKe plays a pivotal role in the proliferation and survival of glioma cells, and indicate that suppression of IKKe leads to inhibition of cell proliferation.

Suppression of IKKE induces cell cycle arrest. To identify the mechanism for this effect on cell proliferation, we performed cell cycle analysis. We observed a significant decrease in the proportion of cells in G0/G1 in cells transfected with IKKe siRNA-3 compared with scrambled siRNA controls (U251; $68.7 \%$ vs $51.8 \%$, p<0.05, LN229; $65.5 \%$ vs $52.3 \%$, p<0.05) (Fig. 3C). This was also accompanied by a reduction in the percentage of S-phase cells. These results suggest that knock- 

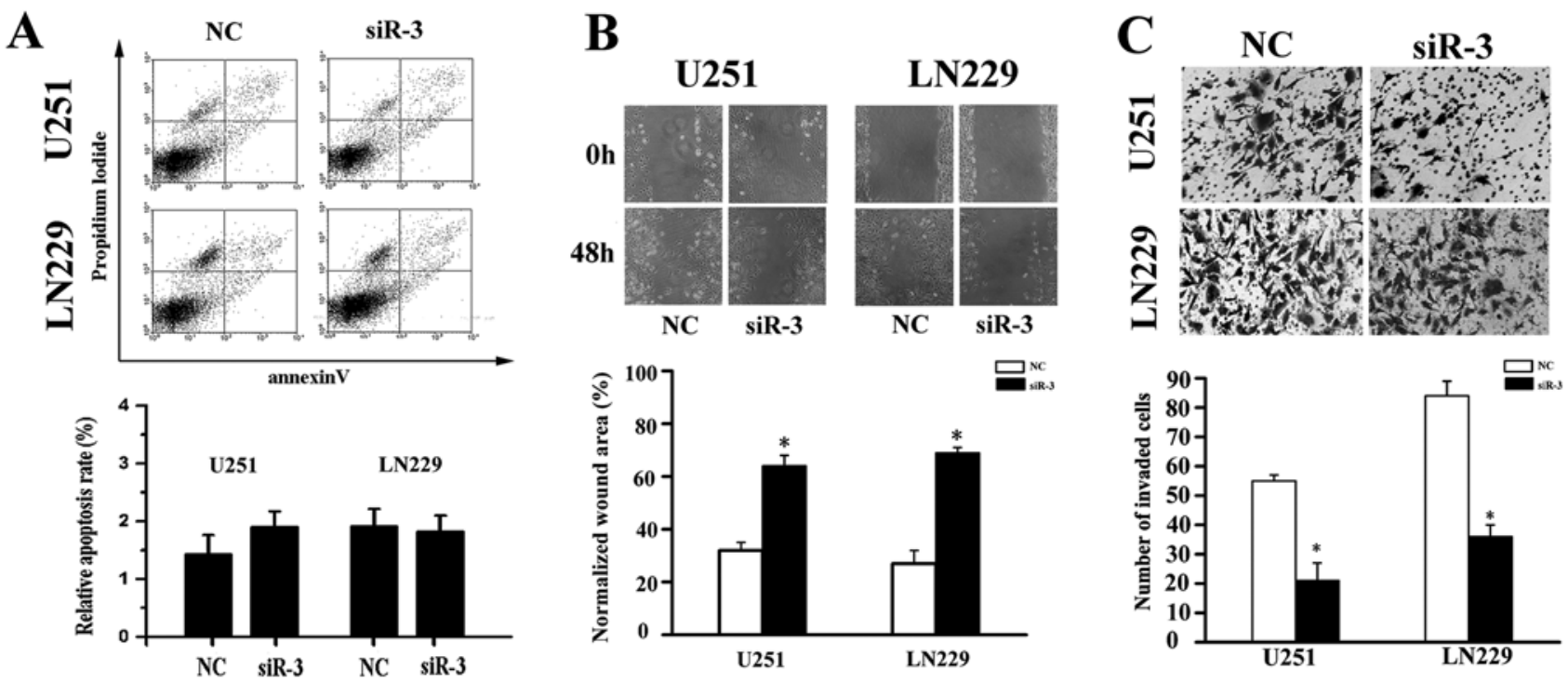

Figure 4. Effect of IKK $\varepsilon$ knockdown on invasion and apoptosis of glioma cells. (A) Apoptosis assay in U251 and LN229 cells after siRNA-NC or IKK $\varepsilon$ siRNA treatments. (B) IKKe knockdown inhibits migration of U251 and LN229 cells. Compared with cells transfected with scrambled siRNA, the cells treated with siR-3 showed a wider wound area $48 \mathrm{~h}$ after wound generation. The normalized wound area was calculated by the software Tscratch. (C) Cell invasion assays using transwell coated with Matrigel. Significant reduction of invasion was observed after silencing IKKe expression in U251 and LN229 cells.

down of $\mathrm{IKK} \varepsilon$ expression can induce cell arrest in the $\mathrm{G} 0 /$ G1 phase, delay the progression of cell cycle, and inhibit cell proliferation.

Knockdown of IKKe induces negligible apoptosis. To determine whether IKKe knockdown affects apoptosis, we performed Annexin-V staining of glioma cells $48 \mathrm{~h}$ after transfection with IKKe siRNA-3. We observed no significant difference in the percentage of Annexin-V-positive apoptotic cells in $\mathrm{IKK \varepsilon}$ siRNA-treated cells compared with controls (U251; $1.9 \%$ vs $1.4 \%, \mathrm{p}=0.43$, LN229; $1.9 \%$ vs $1.8 \%, \mathrm{p}=0.78$ ) (Fig. $4 \mathrm{~A})$. No significant distinction was observed in this study, suggesting that knockdown of IKKe alone may not be involved in glioma cell apoptosis.

Silencing of IKKE inhibits cell migration and invasion. To investigate the role of IKKe in glioma cell migration, we adopted a classic wound healing assay in which a monolayer of adherent cells is scratched and the migration of cells to the wound area was analyzed at different time points. Knockdown of $\mathrm{IKK \varepsilon}$ inhibited wound healing compared with cells transfected with scrambled siRNA control after $48 \mathrm{~h}$, indicating impaired migration (Fig. 4B). Because both cell migration and invasion are critical properties for metastases, we further investigated the invasive capacities of glioma cells using cell invasion assays. Knockdown of IKKe significantly impaired the invasion of both U251 and LN229 cells across a trans-well chamber compared with control siRNA by $62 \%$ and $57 \%$, respectively (Fig. 4C). These data indicate that IKK $\varepsilon$ plays a role in glioma cell migration and invasion.

Downregulation of IKKE impairs nuclear translocation of $N F-\kappa B$. NF- $\kappa \mathrm{B}$ is constitutively activated in several human cancers, including glioma $(15,16)$. NF- $\kappa \mathrm{B}$ activity is controlled

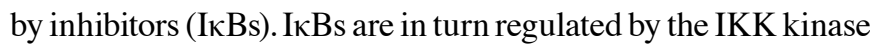
in response to various cellular stimuli, resulting in ubiquitinmediated protein degradation of I $\mathrm{BB}$ and subsequent $\mathrm{NF}-\kappa \mathrm{B}$ translocation into the nucleus $(9,17)$. However, the mechanism underlying the increase in NF- $\kappa \mathrm{B}$ activity in human glioma is not well understood. To determine whether the knockdown of IKKe affects constitutive NF- $\kappa \mathrm{B}$ activity in glioma cells, we analyzed the expression of p65 in cytoplasmic and nuclear extracts of transfected cells. As shown Fig. 5A, the nuclear translocation of $\mathrm{NF}-\kappa \mathrm{B}$ p65 protein was markedly decreased in both U251 and LN229 cells treated with IKKe siRNA compared with control cells. This was further confirmed by immunocytochemical and fluorescence analysis (Fig. 5B and C). These results indicate that

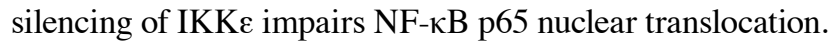

Silencing of IKKe affects $N F-\kappa B$ downstream targets. NF- $\kappa \mathrm{B}-$ mediated cell proliferation and invasion is well documented in glioma (18). Targeted knockdown of IKKe in glioma cells decreased expression of NF- $\kappa \mathrm{B}$ target genes including c-myc, cyclin D1, Bcl-2, MMP-9 and VEGF at the level of mRNA (Fig. 5D) and protein (Fig. 5E) (both $\mathrm{P}<0.05$ ). Intriguingly, suppression of IKKe did not affect the expression of Bcl-2 in either U251 or LN229 glioma cell lines. In most cases, inactive $\mathrm{NF}-\kappa \mathrm{B}$ proteins are sequestered in the cytoplasm in a complex with an inhibitor protein, termed I $\mathrm{B}$, in particular, the I $\mathrm{B} \alpha$ isoform. Activation of $\mathrm{NF}-\kappa \mathrm{B}$ proceeds following the activation of IKK $\varepsilon$, which phosphorylates I $\kappa \mathrm{B} \alpha$, causing its degradation. We found that U251 and LN229 cells treated with IKKe siRNA exhibited higher levels of I $\mathrm{B} \alpha$ compared with control siRNA cells $(\mathrm{P}<0.05)$. These data support the notion that IKKe may contribute to the regulation of $\mathrm{NF}-\kappa \mathrm{B}$ signaling via the regulation of $\mathrm{I} \kappa \mathrm{B} \alpha(8,10)$. Taken together, our results demonstrate that IKK $\varepsilon$ expression modulates the expression of NF- $\kappa \mathrm{B}$ target genes involved in glioma cell invasion and proliferation. 
A
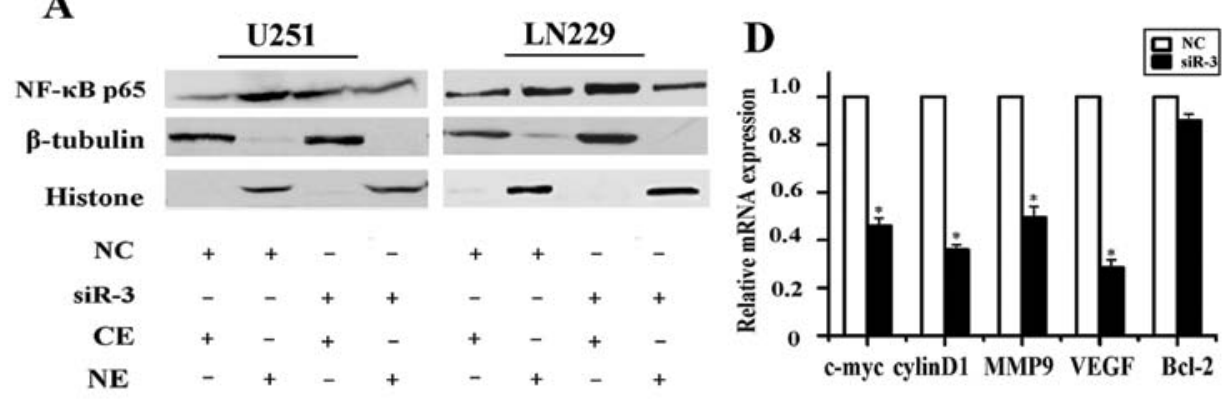

B
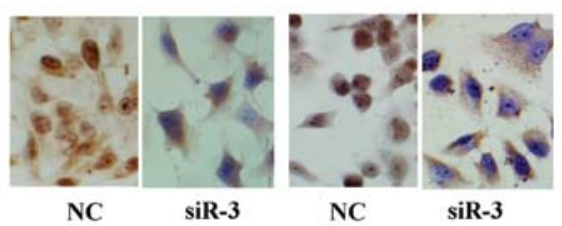

C
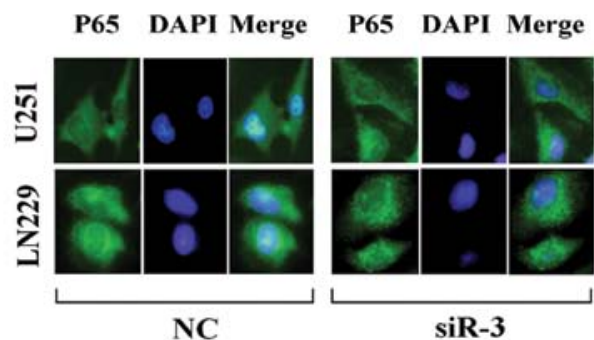

$\mathbf{E}$

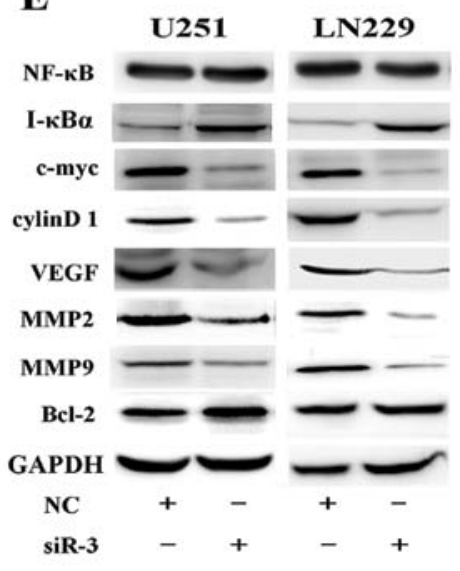

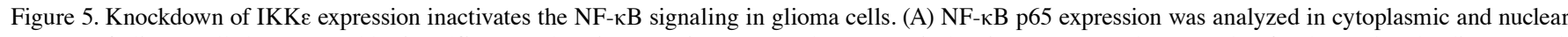
extracts of glioma cells by western blotting. (CE, cytoplasmic extraction; NE, nuclear extraction). Histone was used as a marker for the nuclear loading control. $\beta$-tubutin was used as a cytoplasmic loading control. (B) Immunocytochemistry and (C) cell immunofluorescence assay using anti-NF- $\mathrm{kB}$ p65 antibody in U251 and LN229 cells. DAPI staining was employed as a nuclear counter stain (x200). (D) The level of mRNA associated with cell invasive ability, apoptosis and cell proliferation was detected by quantitative real-time PCR in U251 and LN229 cells $48 \mathrm{~h}$ after transfection. (E) Western blot analysis of c-myc, MMP2/9, cyclinD1,

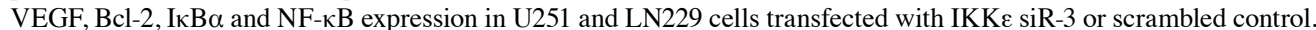

A

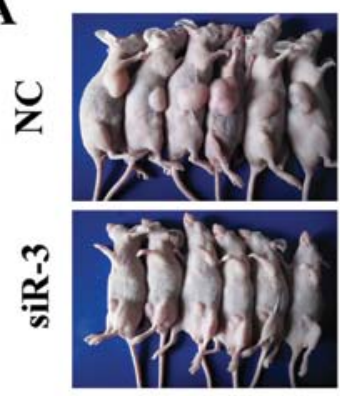

C

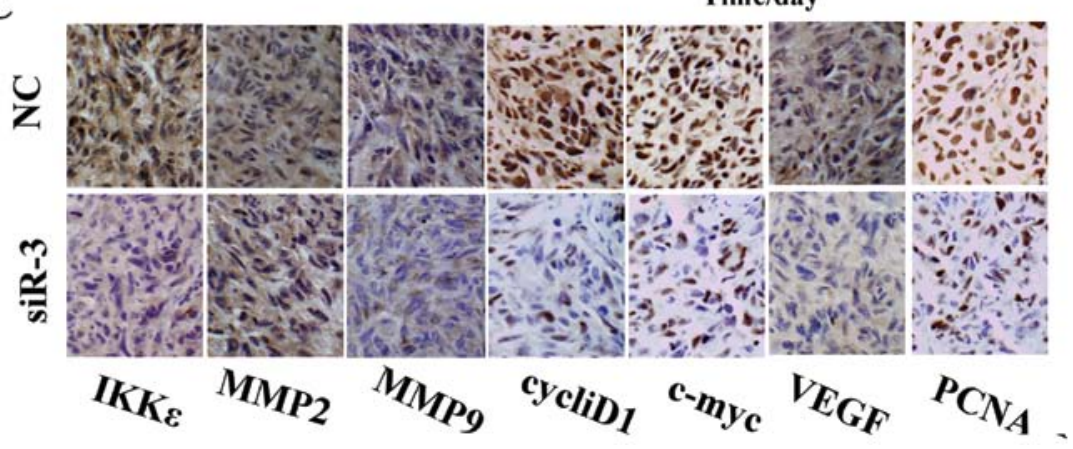

Figure 6. Treatment of nude mice bearing subcutaneous xenograft gliomas with IKK $\varepsilon$ siRNA. (A) Tumors treated with IKKe siRNA were significantly smaller than NC-siRNA treated tumors. (B) Tumor growth in nude mice treated with IKKe siRNA compared with that in NC-siRNA treated mice. (C) Immunohistochemistry analysis of expression of IKKe, PCNA, MMP2/9, VEGF, c-myc, cyclin D1 and PCNA in siR-3-treated tumors compared with NC treated tumors (x200). The results were consistent with that observed in vitro. IKKe protein was effectively inhibited by siRNA-3 treatment, resulting in downregulation of IKKe, PCNA, MMP2/9, VEGF, c-myc, cyclin D1 and PCNA in siR-3-treated tumors. 
IKKE downregulation inhibits tumor transformation in a murine xenograft model. Since our in vitro data showed an anti-tumorigenic role for IKKe siRNA, we examined the therapeutic potential of $\mathrm{IKK} \varepsilon$ knockdown in vivo in a mouse xenograft model. Nude mice were subcutaneously inoculated with U251 cells and monitored until the tumor cells had formed palpable tumors with an average volume of $120 \mathrm{~mm}^{3}$ (approximately 7 days). IKKe siRNA or a control siRNA was then administered by intratumoral injections every 2 days for a total of 20 days. All mice were sacrificed on day 21. As shown in Fig. 6A-C, intratumoral delivery of synthetic IKKe siRNA induced a specific inhibitory response and robustly interfered with tumor growth compared with control mice $(\mathrm{P}<0.05)$. To correlate the therapeutic response observed with inhibition of IKK $\varepsilon$, expression of IKKe, MMP2/9, cyclin D1, PCNA, VEGF and c-myc was assessed by immunohistochemical staining. As observed in our in vitro studies, IKKe protein was effectively inhibited by siRNA treatment, and downstream targets MMP-9, cyclin D1, PCNA, VEGF and c-myc were also downregulated in IKK $\varepsilon$ siRNA infected tumors.

\section{Discussion}

IKKe was shown to be upregulated in breast cancer $(8,10)$, ovarian cancer (11) and prostate cancer (12). Recently, Guan et al demonstrated that $\mathrm{IKK} \varepsilon$ is also overexpressed in gliomas, however, expression level was not related to tumor pathological grade (14). Our study revealed that elevated levels of IKKe are more frequently observed in high grade tumors, suggesting that alterations in $\mathrm{IKK} \varepsilon$ expression are an early event in the development of some gliomas. A similar result was shown for IKKe expression in ovarian cancer progression (11). Further studies with more clinical samples are required to substantiate this observation.

Glioma is a highly invasive tumor, associated with high morbidity and mortality. Despite advances in the diagnosis and treatment of gliomas during the past several decades, the prognosis of patients remains poor. Indeed the 5-year survival rate for stage III and IV disease is only $1.9-9.8 \%$ when patients are treated with temozolomide or radiotherapy alone (19). Understanding the molecular mechanisms underlying gliomagenesis is necessary for the development of novel and promising therapeutic solutions.

Bohem et al confirmed that IKKe was required for the proliferation and survival of ZR-75-1 cells and also showed that knockdown of IKKi was required to diminish the viability of MCF-7 cells (10). A similar inhibitory effect on cell proliferation was also observed following $\mathrm{IKK \varepsilon}$ knockdown in HeLa cells and ovarian cancer cells $(9,11)$. In agreement with these findings, we found that targeted knockdown of IKKe significantly suppresses glioma cell proliferation. Previous studies by Bin et al also showed that inhibition of IKKe expression by siRNA reduced the ability of breast cancer cells to form anchorage-independent foci in six-well plates (20). Consistent with these observations, we show knockdown of IKK $\varepsilon$ in two IKK $\varepsilon$-expressing cell lines, U251 and LN229, significantly impaired foci formation. Importantly, this reduction of foci forming potential correlated with inhibition of tumors in nude mice treated with IKKe siRNA (21).
Lastly, we examined the effect of IKKe on cell apoptosis. The role of IKKe in cell apoptosis remains controversial. One study reported that $\mathrm{IKK} \varepsilon$ inhibition induced apoptosis in HeLa cells (22). A recent study revealed that shRNA-mediated knockdown of IKK $\varepsilon$ in glioma promotes cleavage and activation of caspase 3, decreasing Bcl-2 expression and inducing apoptosis via activation of NF- $\kappa \mathrm{B}$ signaling (14). In contrast, knockdown of IKK $\varepsilon$ in the human A2780 ovarian cancer cell line did not affect apoptosis (11). In the current study, we observed negligible apoptosis in glioma cells after IKKe inhibition. These controversial reports suggest that apoptosis in glioma cells may be independent of IKKe-mediated signaling pathway. Since induction of apoptosis is determined by a balance of multiple pro-apoptotic and antiapoptotic agents (23), this observation might be explained by the recruitment of other anti-apoptotic factors that may compensate for IKKe silencing.

Cell invasion, angiogenesis and tumor growth are complex mechanisms that involve a variety of biochemical and cellular processes (24). The degree of primary brain tumor growth is directly correlated with its invasive potency and angiogenesis (25). Accumulating evidence implicates NF- $\kappa \mathrm{B}$ and $\mathrm{NF}-\kappa \mathrm{B}-$ related IKKs in cell invasion and tumor metastasis $(26,27)$. For example, study of IKK $\alpha^{\mathrm{AA}}$ knock-in mice, which express a catalytically inactive kinase mutant, revealed an important role for IKK $\alpha$ in the development of metastasis, in addition, Luo et al also demonstrated that blocking IKK $\alpha$ activation resulted in inhibition of prostate cancer metastasis in TRAMP mice (28). Based on this, it is of great interest to elucidate whether silencing of IKK $\varepsilon$ is associated with inhibition of glioma cell invasion. Our in vitro migration and invasion assays indicate that glioma cell invasion and migration properties are significantly inhibited following IKKe silencing, highlighting an important role for $\mathrm{IKK} \varepsilon$ in these tumorigenic processes.

$\mathrm{NF}-\kappa \mathrm{B}$ is a transcription factor that plays a key role in carcinogenesis by controlling expression of several oncogenes, tumor suppressor genes, growth factors and cell adhesion molecules $(29,30)$. NF- $\kappa \mathrm{B}$ is comprised of two subunits, most commonly p65 and p50, that are typically restricted in the cytoplasm by the I $\kappa \mathrm{B}$ inhibitors. I $\mathrm{B}$ activity is controlled by the IKK kinase, which responds to cellular stimuli by phosphorylation of $\mathrm{I} \kappa \mathrm{B}$, resulting in ubiquitin-mediated protein degradation. Subsequently, $\mathrm{NF}-\kappa \mathrm{B}$ is released and translocated into nucleus, stimulating an array of target genes promoting cell proliferation and invasion, and preventing apoptosis (31). Previous studies have shown that overexpression of IKKE leads to $\mathrm{I} \kappa \mathrm{B} \alpha$ degradation $(8,10)$. Ectopic expression of IKK $\varepsilon$ induced p65 phosphorylation, NF- $\kappa \mathrm{B}$ activation and NF- $\kappa \mathrm{B}-$ dependent target gene expression. In stimulated T-cells, IKKe has also been shown to enhance the activity of p65 via serine468 phosphorylation (32). Our studies show that NF- $\kappa$ B p65 nuclear translocation is significantly arrested in U251 and

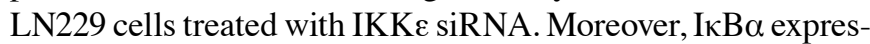
sion was increased in cells treated with IKKe siRNA. Taken together, these data suggest that IKKe may promote malignant transformation, proliferation and invasiveness of glioma cells via activation of $\mathrm{NF}-\kappa \mathrm{B}$.

PCNA expression may be used as a marker of cell proliferation because cells at the G1/S phase may be extended when proliferating $(33,34)$. Cyclin D1 is overexpressed in various tumors and promotes the G1/S transition, leading to cell prolif- 
eration (35). Previous studies observed that the expression of an inactive IKKe kinase (K38A), led to decreased activation of $\mathrm{NF}-\kappa \mathrm{B}$ element-driven cyclin D1 and relB promoters (8). IKKe is also sufficient to activate cyclin D1 in ER-negative and ER-positive ovarian cancer cells (11). Expression of Myc family members is also associated with neurogenic tumors and there is evidence of Myc gene amplification in human brain cancer (36). Superactivation of MMP-9 is associated with the pathogenesis and progression of gliomas $(37,38)$. NF- $\kappa \mathrm{B}$ can induce the expression of MMP-9 by direct promoter regulation (39). $\mathrm{NF}-\kappa \mathrm{B}$ can also regulate MMP-2 activity indirectly via control of an enzyme mediating MMP-2 post-translational processing (40).

Based on this, to further investigate the potential molecular mechanisms involved, we examined expression of VEGF, Bcl-2, Cyclin D1, c-myc and MMP-9 in vitro. Inhibition of $\mathrm{IKK} \varepsilon$ resulted in a significant decrease in $\mathrm{NF}-\kappa \mathrm{B}$ target gene mRNA and protein levels, excluding Bcl-2. Our results suggest that the downregulation of IKKe results in inhibition of $\mathrm{NF}-\kappa \mathrm{B}$ downstream targets. Although IKK $\varepsilon$ overexpression has been associated with the enhanced proliferation and invasion of many tumor cell types in vitro, few studies have investigated the role of $\mathrm{IKK \varepsilon}$ in promoting tumorigenesis in vivo. Using a U251 GBM xenograft model, we show, for the first time, that inhibition of IKKe using an IKKe-specific siRNA, suppresses tumor growth. Consistent with this phenotype, we observed decreased expression of the NF- $\kappa \mathrm{B}$ targets, PCNA, cyclin D1, c-myc and MMP-2/9, suggesting that attenuated tumor progression following IKKe knockdown may be attributed to decreased activation of the NF- $\mathrm{BB}$ signaling pathway.

In conclusion, the key finding of our study is that IKKe expression is drastically upregulated in clinical glioma specimens compared with normal brain tissue and deregulation of IKKe is positively correlated to glioma pathological grade. Cell proliferation, viability, speed of migration, ability to form anchorage-independent colonies and invasive capability of glioma cells is reduced upon IKKe silencing, highlighting the role for IKKe in these key tumorigenic phenotypes. Mechanistically, we show that IKKe is involved in modulation of the $\mathrm{NF}-\kappa \mathrm{B}$ signaling pathway, by directly attenuating $\mathrm{NF}-\kappa \mathrm{B}$ translocation from cytoplasm to nucleus. Furthermore, our in vivo data demonstrate significant growth inhibition of established neurospongioma xenografts by intratumoral delivery of synthetic IKKe siRNA oligonucleotides, supporting the therapeutic potential of this novel RNAi technique.

\section{Acknowledgements}

This project was supported by National Natural Science Foundation of China (no. 81172405).

\section{References}

1. James CD and Olson JJ: Molecular genetics and molecular biology advances in brain tumors. Curr Opin Oncol 8: 188-195, 1996.

2. Westermark B and Nister M: Molecular genetics of human glioma. Curr Opin Oncol 7: 220-225, 1995.

3. Kleihues P, Louis DN, Scheithauer BW, et al: The WHO classification of tumors of the nervous system. J Neuropathol Exp Neurol 61: 215-229, 2002.
4. Surawicz TS, Davis F, Freels S, Laws EJ and Menck HR: Brain tumor survival: results from the National Cancer Data Base. J Neurooncol 40: 151-160, 1998

5. Shimada H, Ambros IM, Dehner LP, et al: The International Neuroblastoma Pathology Classification (the Shimada system). Cancer 86: 364-372, 1999.

6. Peters RT, Liao SM and Maniatis T: IKK is part of a novel PMA-inducible I (kappa) B kinase complex. Mol Cell 5: 513-522, 2000.

7. Sweeney SE, Hammaker D, Boyle DL and Firestein GS: Regulation of c-Jun phosphorylation by the IкB kinase- $\varepsilon$ complex in fibroblast-like synoviocytes. J Immunol 174: 6424-6430, 2005.

8. Eddy SF, Guo S, Demicco EG, et al: Inducible IкB kinase/IкB kinase $\varepsilon$ expression is induced by CK 2 and promotes aberrant nuclear factor- $\kappa \mathrm{B}$ activation in breast cancer cells. Cancer Res 65: 11375-11383, 2005.

9. Adli M and Baldwin AS: IKK-i/IKKe controls constitutive, cancer cell-associated NF- $\mathrm{KB}$ activity via regulation of Ser-536 p65/RelA phosphorylation. J Biol Chem 281: 26976-26984, 2006.

10. Boehm JS, Zhao JJ, Yao J, Kim SY and Firestein R: Integrative genomic approaches identify IKBKE as a breast cancer oncogene. Cell 129: 1065-1079, 2007.

11. Guo JP, Shu SK, He L, et al: Deregulation of IKBKE is associated with tumor progression, poor prognosis, and cisplatin resistance in ovarian cancer. Am J Pathol 175: 324-333, 2009.

12. Péant B, Diallo JS, Dufour F, et al: Over-expression of IкB-kinase- $\varepsilon$ (IKKe/IKKi) induces secretion of inflammatory cytokines in prostate cancer cell lines. Prostate 69: 706-718, 2009.

13. Gebäck T, Schulz MMP, Koumoutsakos P and Detmar M: Short technical reports. Biotechniques 46: 265-274, 2009.

14. Guan H, Zhang H, Cai J, et al: IKBKE is over-expressed in glioma and contributes to resistance of glioma cells to apoptosis via activating NF-kappaB. J Pathol 223: 436-445, 2011.

15. Chen F: Endogenous inhibitors of nuclear factor-kappaB, an opportunity for cancer control. Cancer Res 64: 8135-8138, 2004

16. Harris J, Oliere S, Sharma S, et al: Nuclear accumulation of cRel following C-terminal phosphorylation by TBK1/IKK epsilon. J Immunol 177: 2527-2535, 2006.

17. Sethi G, Sung B and Aggarwal BB: Nuclear factor-kappaB activation: from bench to bedside. Exp Biol Med (Maywood) 233: 21-31, 2008

18. Nakada M, Nakada S, Demuth T, Tran NL, Hoelzinger DB and Berens ME: Molecular targets of glioma invasion. Cell Mol Life Sci 64: 458-478, 2007.

19. Stupp R, Hegi ME, Mason WP, et al: Effects of radiotherapy with concomitant and adjuvant temozolomide versus radiotherapy alone on survival in glioblastoma in a randomised phase III study: 5-year analysis of the EORTC-NCIC trial. Lancet Oncol 10: 459-466, 2009.

20. Qin B and Cheng K: Silencing of the IKKe gene by siRNA inhibits invasiveness and growth of breast cancer cells. Breast Cancer Res 12: R74, 2010.

21. Pearson G, English JM, White MA and Cobb MH: ERK5 and ERK2 cooperate to regulate NF-kappaB and cell transformation. J Biol Chem 276: 7927-7931, 2001.

22. MacKeigan JP, Murphy LO and Blenis J: Sensitized RNAi screen of human kinases and phosphatases identifies new regulators of apoptosis and chemoresistance. Nat Cell Biol 7: 591-600, 2005.

23. Hsu SY, Kaipia A, McGee E, Lomeli M and Hsueh AJ: Bok is a pro-apoptotic Bcl-2 protein with restricted expression in reproductive tissues and heterodimerizes with selective anti-apoptotic Bcl-2 family members. Proc Natl Acad Sci USA 94: 12401-12406, 1997.

24. Hood JD and Cheresh DA: Role of integrins in cell invasion and migration. Nat Rev Cancer 2: 91-100, 2002.

25. Zagzag D, Friedlander DR, Margolis B, et al: Molecular events implicated in brain tumor angiogenesis and invasion. Pediatr Neurosurg 33: 49-55, 2000.

26. Sung B, Pandey MK, Nakajima Y, et al: Identification of a novel blocker of IkappaBalpha kinase activation that enhances apoptosis and inhibits proliferation and invasion by suppressing nuclear factor-kappaB. Mol Cancer Ther 7: 191-201, 2008.

27. Lee TK, Poon RT, Wo JY, et al: Lupeol suppresses cisplatininduced nuclear factor-kappaB activation in head and neck squamous cell carcinoma and inhibits local invasion and nodal metastasis in an orthotopic nude mouse model. Cancer Res 67: 8800-8809, 2007.

28. Luo JL, Tan W, Ricono JM, et al: Nuclear cytokine-activated IKKalpha controls prostate cancer metastasis by repressing Maspin. Nature 446: 690-694, 2007. 
29. Gilmore TD, Koedood M, Piffat KA and White DW: Rel/ NF-kappaB/IkappaB proteins and cancer. Oncogene 13: 1367-1378, 1996.

30. Lee CH, Jeon YT, Kim SH and Song YS: NF-kappaB as a potential molecular target for cancer therapy. Biofactors 29: 19-35, 2007.

31. Naugler WE and Karin M: NF-kappaB and cancer-identifying targets and mechanisms. Curr Opin Genet Dev 18: 19-26, 2008.

32. Mattioli I, Geng H and Sebald A, et al: Inducible phosphorylation of NF-kappa B p65 at serine 468 by T cell costimulation is mediated by IKK epsilon. J Biol Chem 281: 6175-6183, 2006.

33. Yang YC, Huang WF and Chuan LM, et al: In vitro and in vivo study of cell growth inhibition of simvastatin on chronic myelogenous leukemia cells. Chemotherapy 54: 438-446, 2008

34. De Oliveira MG, Lauxen IS, Chaves AC, Rados PV and Sant'Ana FM: Immunohistochemical analysis of the patterns of p53 and PCNA expression in odontogenic cystic lesions. Med Oral Patol Oral Cir Bucal 13: E275-E280, 2008.

35. Yamamoto H, Ochiya T, Takeshita F, et al: Enhanced skin carcinogenesis in cyclin D1-conditional transgenic mice: cyclin D1 alters keratinocyte response to calcium-induced terminal differentiation. Cancer Res 62: 1641-1647, 2002.
36. Trent J, Meltzer P, Rosenblum M, et al: Evidence for rearrangement, amplification, and expression of c-myc in a human glioblastoma. Proc Natl Acad Sci USA 83: 470-473, 1986.

37. Kondraganti S, Mohanam S, Chintala SK, et al: Selective suppression of matrix metalloproteinase- 9 in human glioblastoma cells by antisense gene transfer impairs glioblastoma cell invasion. Cancer Res 60: 6851-6855, 2000.

38. Deryugina EI and Quigley JP: Matrix metalloproteinases and tumor metastasis. Cancer Metastasis Rev 25: 9-34, 2006.

39. Farina AR, Tacconelli A, Vacca A, Maroder M, Gulino A and Mackay AR: Transcriptional up-regulation of matrix metalloproteinase-9 expression during spontaneous epithelial to neuroblast phenotype conversion by SK-N-SH neuroblastoma cells, involved in enhanced invasivity, depends upon GT-box and nuclear factor kappaB elements. Cell Growth Differ 10: 353-367, 1999.

40. Han YP, Tuan TL, Wu H, Hughes M and Garner WL: TNF-alpha stimulates activation of pro-MMP2 in human skin through NF-(kappa)B mediated induction of MT1-MMP. J Cell Sci 114 131-139, 2001. 